\title{
The value and impact of embedded implementation research: insights from Latin America and the Caribbean
}

\author{
Robert Marten ${ }^{1}$, Ludovic Reveiz², Garry Aslanyan³, Freddy Perez ${ }^{2}$ and Abdul Ghaffar ${ }^{1}$
}

Suggested citation Marten R, Reveiz L, Aslanyan G, Perez F, and Ghaffar A. The value and impact of embedded implementation research: insights from Latin America and the Caribbean. Rev Panam Salud Publica. 2021;45:e110. https://doi.org/10.26633/RPSP.2021.110

Embedded research is carried out as an integrated and systematic part of health decision and policy making and implementation. (1) It means continuous collaboration between decision makers, researchers, and communities. Embedded research focuses on systems-level challenges and illuminates context-specific factors for real-world health programs, policy and system decisions. It improves ownership and implementation.(2) With this in mind, a joint initiative between the Alliance for Health Policy and Systems Research (Alliance HPSR), the Pan American Health Organization (PAHO), and the World Health Organization (WHO) Special Programme for Research and Training in Tropical Diseases (TDR) issued an open call for researchers and policy and decision makers to identify challenges requiring embedded research to accelerate progress towards the SDGs in the Latin American and Caribbean (LAC) region and provided technical cooperation throughout the process. Following an open call for applications and reviewing more than 200 research proposals, 13 teams from 11 low- and middle-income countries in the LAC region were selected from Argentina, Bolivia, Brazil, Colombia, Dominican Republic, Ecuador, Guatemala, Guyana, Haiti, Paraguay, and Peru. This supplement of the Pan American Journal of Public Health presents the findings of these embedded implementation research studies. It showcases the value of embedded research and details the impact of this type of work with concrete examples. The results of the papers presented in this supplement identify an increasingly recognized need to focus on developing capacity to collaborate through multisectoral action to achieve the SDGs.

Building on methodological innovations in the WHO Strategy on Health Policy and Systems Research (2012) and the WHO World Health Report on Research for Universal Health
Coverage (2013) as well as previous collaboration between PAHO, the Alliance HPSR and TDR, embedded research as an approach is increasingly valued by policymakers to conceptualize and implement health interventions. The ongoing COVID-19 pandemic exemplifies the close links between policy and research (3) and the need for much greater interdisciplinarity (4). Summarizing their work as a technical support center, Becerril-Montekio et al. maintain that this experience and the results explained in this special issue confirm the value of such initiatives. Mariani et al. evaluate primary health care functions from the perspective of patients with tuberculosis from slums in the city of Buenos Aires, Argentina, and provide insights on how these services might be improved (5). In another example, Polanco-Pasaje et al. evaluate tuberculosis care in Colombia's indigenous population and identify existing gaps (6).

These research studies also document how embedded research can impact and improve policy implementation. For example, Diez-Canseco et al. analyze the implementation of mental health centers in Peru, and highlight their impact on local communities (7). Barreto et al. detail how research improved the development of Brazil's national childbirth guidelines; more specifically, research helped identify and overcome barriers for implementation (8) and detail how professional training and culture, social culture, and political as well as management issues are critical points for consideration (9).

The embedded research studies in this supplement also reveal the critical importance of engaging communities and cultivating capacity to collaborate with other sectors to achieve health goals. Laureano-Eugenio et al. reviewed Guatemala's Healthy Municipalities strategy to improve its implementation; they documented potential for improvements in terms of

\footnotetext{
1 Alliance for Health Policy and Systems Research, World Health Organization, Geneva, Switzerland

2 Pan-American Health Organization, Washington, DC, United States of America
}

\footnotetext{
3 Special Programme for Research and Training in Tropical Diseases, World Health Organization, Geneva, Switzerland
}

This is an open access article distributed under the terms of the Creative Commons Attribution-NonCommercial-NoDerivs 3.0 IGO License, which permits use, distribution, and reproduction in any medium, provided the original work is properly cited. No modifications or commercial use of this article are permitted. In any reproduction of this article there should not be any suggestion that PAHO or this article endorse any specific organizatio or products. The use of the PAHO logo is not permitted. This notice should be preserved along with the article's original URL. Open access logo and text by PLoS, under the Creative Commons Attribution-Share Alike 3.0 Unported license. 
promoting and strengthening social participation as well as insufficient investments in working on the social determinants of health (10). In another example, Sacoto et al. studied an initiative focused on preventing non-communicable diseases in Ecuador; they found that insufficient institutionalization could limit the effort's sustainability and that the initiative needs to improve its coordination with other sectors and actors (11). To codify and improve how this is done, as others have noted, there is continued need for supporting the sharing of experiences in multisectoral action beyond health (12).

While there is still room for greater efforts to bridge the gap between researchers and policy and decision makers, papers in this collection demonstrate the value and impact of embedded research. This supplement also highlights continuing challenges, like working with communities and considering multisectorality to advance health goals. To advance this type of work, new approaches are required for supporting research. There is a need to move away from ad-hoc research projects and instead move towards supporting a greater emphasis on developing longer-term and more collaborative partnerships to enable embedded research. The Alliance for Health Policy and Systems Research, the World Health Organization Special Programme for Research and Training in Tropical Diseases and the Pan American Health Organization are committed to moving in this direction.

\section{REFERENCES}

1. Ghaffar A, Langlois EV, Rasanathan K, et al. Strengthening health systems through embedded research. Bull World Health Organ 2017;95:87. doi:10.2471/BLT.16.189126 PMID: http://www.ncbi. nlm.nih.gov/pubmed/28250505 Accessed on July 92021.

2. Swaminathan S, Sheikh K, Marten R, et al. Embedded research to advance primary health care. BMJ Global Health 2020;5:e004684.

3. Yin Y, Gao J, Jones BF, Wang D. Coevolution of policy and science during the pandemic. Science. 2021 Jan 8;371(6525):128-130. doi: 10.1126/science.abe3084. PMID: 33414211.

4. Mol A, Hardon A. What COVID-19 may teach us about interdisciplinarity. BMJ Global Health. 2020;5:e004375.

5. Mariani J, Ferrante D, Battistella G, Langsam M, Pérez F, Macchia A. Evaluation of the first level of care for tuberculosis control in Buenos Aires, Argentina. Rev Panam Salud Publica. 2021;45:e22. DOI: https://doi.org/10.26633/RPSP.2021.22. PMID: 33552149; PMCID: PMC7860151.

6. Polanco-Pasaje JE, Rodríguez-Márquez I, Tello-Hoyos KY, Torres-Pereda P, Guzmán-Salazar BL, Pérez F. Tuberculosis care cascade for the indigenous population in Colombia: an operational research study. Rev Panam Salud Publica. 2021;45:e20. DOI: https://doi.org/10.26633/RPSP.2021.20. PMID: 33643402; PMCID: PMC7901045.

7. Diez-Canseco F, Rojas-Vargas J, Toyama M, Mendoza M, Cavero V, Maldonado H, Caballero J, Cutipé Y. Qualitative study of the implementation of the Continuity of Care and Rehabilitation Program for people with severe mental disorders in Peru. Rev Panam Salud Publica. 2020;44:e169. DOI: https://doi.org/10.26633/ RPSP.2020.169. PMID: 33417655; PMCID: PMC7778464.

8. Barreto JOM, Bortoli MC, Luquine CD Jr, Oliveira CF, Toma TS, Ribeiro AAV, Tesser TR, Rattner D, Vidal A, Mendes Y, Carvalho V, Neri MA, Chapman E. Implementation of national childbirth guidelines in Brazil: barriers and strategies. Rev Panam Salud Publica. 2020;44:e170. DOI: https://doi.org/10.26633/RPSP.2020.170. PMID: 33417646; PMCID: PMC7778467.

9. Vidal ÁT, Barreto JOM, Rattner D. Barriers to implementing childbirth recommendations in Brazil: the women's perspective. Rev Panam Salud Publica. 2021;45:e17. DOI: https://doi.org/10.26633/ RPSP.2021.17. PMID: 33643400; PMCID: PMC7898362.

10. Laureano-Eugenio J, Gómez-Rodríguez RO, Tasejo-Corzantes J, Silvestre Ramírez A, Pretell Aguilar RM, Alcalde-Rabanal JE. Sustainability of the Healthy Municipalities Strategy in Guatemala. Rev Panam Salud Publica. 2021;45:e70. DOI: https://doi.org/10.26633/ RPSP.2021.70. PMID: 34131424; PMCID: PMC8196337.

11. Sacoto F, Torres I, López-Cevallos DF. Sustainability in chronic disease prevention: lessons from the Salud al Paso program in Ecuador. Rev Panam Salud Publica. 2021;45:e30. DOI: https:// doi.org/10.26633/RPSP.2021.30. PMID: 33643405; PMCID: PMC79 01044 .

12. Rasanathan K, Atkins V, Mwansambo C, et al. Governing multisectoral action for health in low-income and middle-income countries: an agenda for the way forward. BMJ Global Health. 2018;3:e000890.

\section{Appreciation}

The Pan American Journal of Public Health thanks the Alliance for Health Policy and Systems Research (Alliance HPSR) and the UNICEF/UNDP/World Bank/ WHO Special Program for Research and Training in Tropical Diseases (TDR) and their funders for their financial and programmatic support for this supplement. 